University of Nebraska - Lincoln

DigitalCommons@University of Nebraska - Lincoln

4-28-1995

\title{
Heterogeneity of Variance by Sire Breed, Sex, and Dam Breed in 200- and 365-Day Weights of Beef Cattle from a Top Cross Experiment
}

\author{
F. A. Rodriguez-Almeida \\ University of Nebraska-Lincoln \\ L. Dale Van Vleck \\ University of Nebraska-Lincoln, dvan-vleck1@unl.edu \\ Larry V. Cundiff \\ University of Nebraska-Lincoln, Icundiff2@unl.edu \\ Stephen D. Kachman \\ University of Nebraska-Lincoln, steve.kachman@unl.edu
}

Follow this and additional works at: https://digitalcommons.unl.edu/animalscifacpub

Part of the Animal Sciences Commons

Rodriguez-Almeida, F. A.; Van Vleck, L. Dale; Cundiff, Larry V.; and Kachman, Stephen D., "Heterogeneity of Variance by Sire Breed, Sex, and Dam Breed in 200- and 365-Day Weights of Beef Cattle from a Top Cross Experiment" (1995). Faculty Papers and Publications in Animal Science. 260.

https://digitalcommons.unl.edu/animalscifacpub/260

This Article is brought to you for free and open access by the Animal Science Department at DigitalCommons@University of Nebraska - Lincoln. It has been accepted for inclusion in Faculty Papers and Publications in Animal Science by an authorized administrator of DigitalCommons@University of Nebraska - Lincoln. 


\title{
Heterogeneity of Variance by Sire Breed, Sex, and Dam Breed in 200- and 365-Day Weights of Beef Cattle from a Top Cross Experiment ${ }^{1,2}$
}

\author{
F. A. Rodríguez-Almeida $a^{* 3}$, L. D. Van Vleck ${ }^{* \dagger}$, L. V. Cundiff ${ }^{\dagger}$ and S. D. Kachman \\ *Departments of Animal Science and ¥Biometry, University of Nebraska, Lincoln 68583-0908 and \\ ${ }^{\dagger}$ Roman L. Hruska U.S. Meat Animal Research Center, ARS, USDA, Clay Center, NE 68933
}

\begin{abstract}
The nature of the heterogeneity of variance for 200- and 365-d weights by sex, sire breed, and dam breed subclasses was studied. Data consisted of records for weaning $(\mathrm{n}=7,829)$ and yearling $(\mathrm{n}=$ 7,367 ) weights of progeny from 673 and 672 sires, respectively, from 22 breeds that have been evaluated in the Germ Plasm Evaluation Program at the U.S. Meat Animal Research Center, Clay Center, NE. Sires were mated to Hereford and Angus cows. Each trait was analyzed separately. Three studies were undertaken separately to investigate heterogeneity due to the different factors (i.e, sire breed, sex, or dam breed). Only data from seven sire breeds were used to study the factor sire breed, but all data (22 sire breeds) were used to study the factors sex and dam breed. In each study, three sire and dam models with records of animals of the four sex $\times$ dam breed combinations considered different traits and with the same model equation, but covariance structures for random effects (sires, dams, and residuals) of increasing generality were fitted. First, (co)variances across subclasses were assumed equal. Second, correlations
\end{abstract}

and fractions of phenotypic variance were assumed equal but phenotypic variance differed by sire breed, sex, or dam breed as appropriate. Third, variances and covariances were different for each subclass of the factor under study. Variance components were estimated by derivative-free REML. Models for each trait and each factor were compared through likelihood ratio tests. For both traits, variances differed $(P<$ .02 ) in scale, but not as fractions of phenotypic variance $(P>.10)$, by sire breed and sex subclasses. Variances were not different $(P>.10)$ by dam breed subclasses, either in scale or as fractions of phenotypic variance. Estimates of correlations among genetic effects on weights of calves from different sex-dam breed subclasses were at least .85. Across all sex, sire breed, and dam breed subclasses, pooled estimates of sire and dam variances as fractions of phenotypic variance were, respectively, .06 and .39 for weaning weight and .11 and .24 for yearling weight. The conclusion is that the assumption of equal phenotypic variances among sire breeds and between sexes may not be appropriate in genetic evaluations.

Key Words: Variance, Heterogeneity, Weight Traits, Beef Cattle

J. Anim. Sci. 1995. 73:2579-2588

\section{Introduction}

Differences in variances among breeds of beef cattle have been of concern when procedures for multibreed genetic evaluations have been proposed (Elzo and Famula, 1985; Arnold et al., 1992). Van Vleck (1994)

\footnotetext{
${ }^{1}$ Published as paper no. 10872, Journal Ser., Nebraska Agric. Res. Div., Univ. of Nebraska, Lincoln 68583-0908.

${ }^{2}$ This study was conducted while the first author was a graduate student with financial support of Consejo Nacional de Tecnologia (CONACYT) and Universidad Autónoma de Chihuahua, México.

${ }^{3}$ Current address: Facultad de Zootecnia, UACH. Apdo. Postal 4-28, Chihuahua, Mexico C.P. 31031.

Received September 12, 1994.

Accepted April 28, 1995.
}

pointed out that different variances for different sire breeds may not be very important for estimating sire breed mean differences required to obtain interbreed expected progeny differences (Notter, 1989; Cundiff, 1994), but differences in variances could be of consequence for the prediction of the random genetic merit of a sire with respect to the mean of its breed. In addition, Van Vleck (1994) indicated that it could be necessary to consider differences in variances due to dam breeds.

Garrick et al. (1989) found that heterogeneity of variances in beef cattle can exist not only with respect to breed composition, but also according to sex of the calf, which could result in reranking of animals to be selected if those differences were ignored (Garrick et al., 1989; Núñez-Domínguez et al., 1995), with the 
Table 1. Distribution of 22 sire breeds used in Germplasm Evaluation Program through five cycles

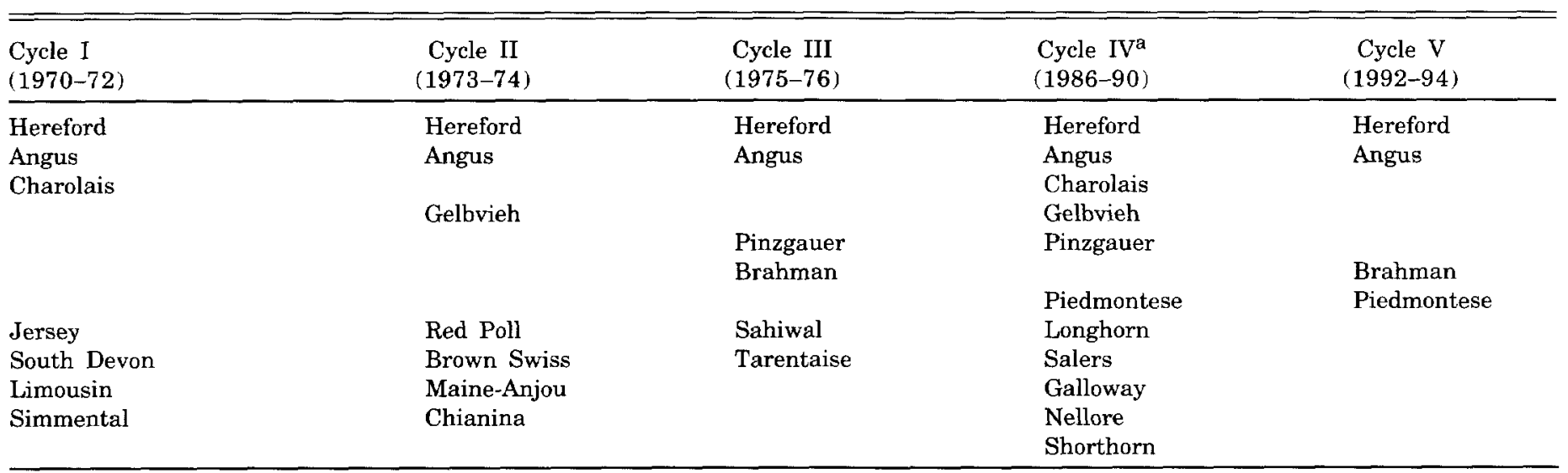

aIn Cycle IV, new samples of Hereford, Angus, Charolais, Gelbvieh, and Pinzgauer sires born after January 1982 were included in addition to the original Hereford and Angus sires.

result that genetic progress could be reduced (Vinson, 1987).

Heterogeneity of variance can apply to residuals or other random effects in the model. Treating records of animals in subclasses with different variances as being different traits accounts for the heteroscedasticity (Henderson, 1984; Gianola, 1986). However, the number of parameters to estimate would be reduced if variances were different in scale but ratios of them were similar among subclasses, and if correlations between random effects in different subclasses were not different from unity, which, in turn, reduces the number of equations for random effects in the mixedmodel equations (Quaas et al., 1989).

Thus, the purpose of this study was to investigate the nature of heterogeneity of variance associated with sex, sire breed, and dam breed in 200- and $365-d$ weights of calves from Hereford and Angus dams sired by bulls of 22 breeds.

\section{Materials and Methods}

Description of Data. Records of progeny of 673 and 672 sires for weaning (W) and yearling ( $\mathrm{YW}$ ) weights, respectively, from 22 of the breeds that have been evaluated in the Germ Plasm Evaluation Program ( GPE) at the Roman L. Hruska U. S. Meat Animal Research Center, Clay Center, NE, were used. Weaning ( $\mathrm{n}=7,829)$ and yearling $(\mathbf{n}=7,367)$ weights were preadjusted to 200 and $365 \mathrm{~d}$ of age, respectively.

The GPE program has been conducted in five cycles. Table 1 shows the distribution of the 22 sire breeds considered in this study through the different cycles. All data from the first four cycles were included, but for cycle $\mathrm{V}$ only records from the first calf crop born in 1992 and from sire breeds that were used in previous cycles were considered. The same Hereford and Angus bulls were used by artificial insemination in all cycles to create ties for breed comparisons. In addition, new samples of Hereford, Angus, Charolais, Pinzgauer, and Gelbvieh bulls were introduced in Cycle IV. Brahman and Piedmontese sires were also used in Cycle $\mathrm{V}$ as a basis of comparison for other breeds being evaluated in cycle $V$, but few data were available for those breeds and were not included in the present study.

All calves had Hereford ( $\mathbf{H}$ ) or Angus ( A) dams. The foundation cows were purchased as calves at weaning from commercial producers in Nebraska; thus, pedigree information was not available for them.

Management was previously reported by Smith et al. (1976a,b), Gregory et al. (1978, 1979a,b), Cundiff et al. $(1981,1984,1993,1994)$, and Núñez-Domínguez et al. (1993). In general, calves were born in the spring, males were castrated within $24 \mathrm{~h}$, and all calves were creep-fed whole oats from mid-July until weaning in late October. For the first three cycles, weaning was at approximately $200 \mathrm{~d}$ of age, except that calves born in 1974 were weaned on average at $167 \mathrm{~d}$ of age due to drought conditions. In later cycles, weaning was on average at $170 \mathrm{~d}$ of age. After weaning, heifers were managed to calve first at $2 \mathrm{yr}$ of age and were fed a diet, according to their stage of growth, of approximately 50\% corn silage and 50\% alfalfa or grass haylage, on a dry matter basis, plus protein and mineral supplement. After weaning, steers received a high-energy density diet for approximately $196 \mathrm{~d}$ for the first three cycles and for an average of $230 \mathrm{~d}$ for later cycles, after a preconditioning period of 25 to $58 \mathrm{~d}$.

\section{Heterogeneity of Variance Due to Sire Breed}

Because few records were available for some of the sire breeds, data for only seven sire breeds with most of the records $(4,440$ and 4,164 , for WW and YW, respectively) were used to investigate heterogeneity of variance due to sire breed subclasses. Table 2 shows the number of sires for each breed and number of records for each sire breed-dam breed-sex subclass. 
Table 2. Numbers of sires and records for 200- and 365-day weights of calves from seven sire breeds

\begin{tabular}{|c|c|c|c|c|c|c|c|c|c|}
\hline \multirow[b]{3}{*}{ Sire breed } & \multirow[b]{3}{*}{ Sires } & \multicolumn{4}{|c|}{$200-d w t$} & \multicolumn{4}{|c|}{$365-\mathrm{d}$ wt } \\
\hline & & \multicolumn{2}{|c|}{ Hereford dams } & \multicolumn{2}{|c|}{ Angus dams } & \multicolumn{2}{|c|}{ Hereford dams } & \multicolumn{2}{|c|}{ Angus dams } \\
\hline & & Males & Females & Males & Female & Males & Female & Males & Female \\
\hline Hereford & 82 & 217 & 183 & 401 & 371 & 211 & 181 & 392 & 310 \\
\hline Angus & $93^{\mathrm{a}}$ & 331 & 286 & 259 & 193 & 328 & 248 & 253 & 192 \\
\hline Charolais & 64 & 132 & 122 & 150 & 124 & 129 & 122 & 148 & 91 \\
\hline Gelbvieh & 29 & 102 & 106 & 119 & 82 & 101 & 106 & 119 & 80 \\
\hline Pinzgauer & 25 & 130 & 130 & 152 & 146 & 128 & 101 & 149 & 111 \\
\hline Simmental & 27 & 83 & 92 & 94 & 97 & 81 & 91 & 93 & 65 \\
\hline Limousin & 20 & 87 & 84 & 89 & 78 & 86 & 83 & 87 & 78 \\
\hline Total & $340^{\mathrm{a}}$ & 1,082 & 1,003 & 1,264 & 1,091 & 1,064 & 932 & 1,241 & 927 \\
\hline
\end{tabular}

aThese numbers correspond to number of sires for 200-d weight, but there was one less sire for 365-d weight.

Sire breeds included in this part of the study were $\mathrm{H}$, A, Charolais, Gelbvieh, Pinzgauer, Simmental, and Limousin, with a total of 340 and 339 sires for WW and YW, respectively. The Polled Hereford breed was assumed to have the same variances as Hereford, but it was considered to be a genetic group with different means for the traits analyzed. Few cows had more than one progeny with a record within each sire breed; however, the number of cows with a calf by more than one sire breed was large enough to estimate (co)variances due to dam effects.

Each trait was analyzed separately. To study heterogeneity due to sire breed, three multivariate sire and dam models with records of animals of the four combinations of sex (male $[\mathbf{M}]$, female $[\mathbf{F}]$ ) and breed of dam (H, A) considered different traits, and with the same model equation but differing in covariance structure were fitted. The model equations were as follows:

$$
\begin{gathered}
{\left[\begin{array}{c}
\mathbf{y}_{\mathrm{MH}} \\
\mathbf{y}_{\mathrm{FH}} \\
\mathbf{y}_{\mathrm{MA}} \\
\mathbf{y}_{\mathrm{FA}}
\end{array}\right]=\left[\begin{array}{cccc}
\mathbf{x}_{\mathrm{MH}} & 0 & 0 & 0 \\
0 & \mathbf{x}_{\mathrm{FH}} & 0 & 0 \\
0 & 0 & \mathbf{x}_{\mathrm{MA}} & 0 \\
0 & 0 & 0 & \mathbf{x}_{\mathrm{FA}}
\end{array}\right]\left[\begin{array}{c}
\boldsymbol{\beta}_{\mathrm{MH}} \\
\boldsymbol{\beta}_{\mathrm{FH}} \\
\boldsymbol{\beta}_{\mathrm{MA}} \\
\boldsymbol{\beta}_{\mathrm{FA}}
\end{array}\right]} \\
+\left[\begin{array}{cccc}
\mathbf{Z}_{\mathrm{MH}} & 0 & 0 & 0 \\
0 & \mathbf{Z}_{\mathrm{FH}} & 0 & 0 \\
0 & 0 & \mathbf{Z}_{\mathrm{MA}} & 0 \\
0 & 0 & 0 & \mathbf{z}_{\mathrm{FA}}
\end{array}\right]\left[\begin{array}{c}
\mathbf{s}_{\mathrm{MH}} \\
\mathbf{s}_{\mathrm{FH}} \\
\mathbf{s}_{\mathrm{MA}} \\
\mathbf{s}_{\mathrm{FA}}
\end{array}\right] \\
+\left[\begin{array}{ccccc}
\mathbf{W}_{\mathrm{MH}} & \mathbf{0} & 0 & 0 \\
0 & \mathbf{w}_{\mathrm{FH}} & 0 & 0 \\
0 & 0 & \mathbf{w}_{\mathrm{MA}} & 0 \\
0 & 0 & 0 & \mathbf{w}_{\mathrm{FA}}
\end{array}\right]\left[\begin{array}{l}
\mathbf{d}_{\mathrm{MH}} \\
\mathbf{d}_{\mathrm{FH}} \\
\mathbf{d}_{\mathrm{MA}} \\
\mathbf{d}_{\mathrm{FA}}
\end{array}\right]+\left[\begin{array}{l}
\mathbf{e}_{\mathrm{MH}} \\
\mathbf{e}_{\mathrm{FH}} \\
\mathbf{e}_{\mathrm{MA}} \\
\mathbf{e}_{\mathrm{FA}}
\end{array}\right]
\end{gathered}
$$

Combining the four traits the equations can be represented as follows:

$$
\mathbf{y}=\mathbf{X} \boldsymbol{\beta}+\mathbf{Z s}+\mathbf{W} \mathbf{d}+\mathbf{e}
$$

where $\mathbf{y}_{\mathrm{IJ}}=\mathrm{a}$ vector of observations corresponding to the $I J^{\text {th }}$ sex-dam breed subclass; $\beta=$ a vector of fixed effects that includes effects due to genetic group of sire (samples of sires introduced at different times; Table 1 ), birth year of calf and age of dam both within sire breed, and heterosis as a covariate ( 0 for purebreds, 1 for crossbreds); $\mathbf{s}=$ a vector of random sire within genetic group of sire effects; $\mathbf{d}=$ a vector of random dam effects; $\mathbf{e}=$ a vector of residuals; $\mathbf{X}, \mathbf{Z}$, and $\mathbf{W}=$ incidence matrices relating observations to the fixed,

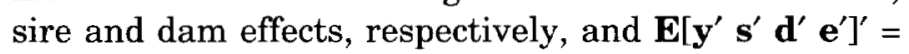



Because few cows had more than one progeny within each sire breed, variances due to dam effects were assumed to be the same for all sire breeds, that is,

$$
\operatorname{Var}\left[\begin{array}{l}
\mathbf{d}_{\mathrm{MJ}} \\
\mathbf{d}_{\mathrm{FJ}}
\end{array}\right]=\left(\begin{array}{ll}
\boldsymbol{\sigma}_{\mathrm{d}_{\mathrm{MJJ}}}^{2} & \boldsymbol{\sigma}_{\mathrm{d}_{\mathrm{MJ}, \mathrm{FJ}}} \\
\boldsymbol{\sigma}_{\mathrm{d}_{\mathrm{MJ}, \mathrm{FJ}}} & \boldsymbol{\sigma}_{\mathrm{d}_{\mathrm{FJ}}}^{2}
\end{array}\right) \otimes \mathbf{I}_{\mathrm{n}_{\mathrm{J}}}=\mathbf{D}_{\mathrm{J}}
$$

where $\otimes$ is the direct product operator and $n_{J}$ is the total number of dams in the $\mathbf{J}^{\text {th }}$ dam breed, $\mathrm{H}$ or $\mathrm{A}$.

Variance-covariance structures for sire effects and residuals can be represented as the direct sums of submatrices corresponding to each sire breed:



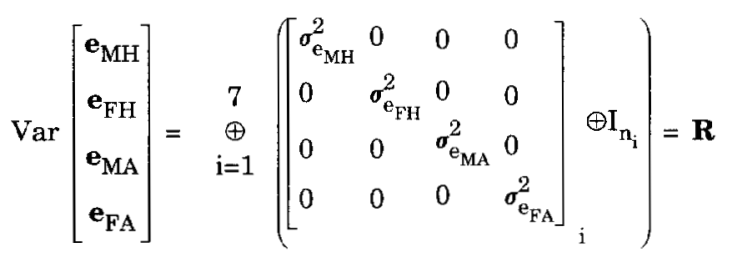


Table 3. Numbers of sires and records for 200- and 365-day weights of calves from 22 sire breeds

\begin{tabular}{|c|c|c|c|c|c|c|c|c|c|}
\hline \multirow[b]{3}{*}{ Sire breed } & \multirow[b]{3}{*}{ Sire } & \multicolumn{4}{|c|}{$200-\mathrm{d} w \mathrm{t}$} & \multicolumn{4}{|c|}{$365-\mathrm{d} w \mathrm{t}$} \\
\hline & & \multicolumn{2}{|c|}{ Hereford dams } & \multicolumn{2}{|c|}{ Angus dams } & \multicolumn{2}{|c|}{ Hereford dams } & \multicolumn{2}{|c|}{ Angus dams } \\
\hline & & Males & Females & Males & Females & Males & Females & Males & Females \\
\hline Brahman & 34 & 59 & 84 & 118 & 123 & 57 & 55 & 117 & 87 \\
\hline Brown Swiss & 11 & 52 & 67 & 66 & 66 & 51 & 67 & 66 & 66 \\
\hline Chianina & 20 & 56 & 48 & 63 & 49 & 56 & 48 & 63 & 49 \\
\hline Galloway & 30 & 36 & 38 & 50 & 39 & 35 & 37 & 50 & 39 \\
\hline Jersey & 33 & 51 & 60 & 80 & 84 & 51 & 60 & 80 & 54 \\
\hline Longhorn & 28 & 45 & 36 & 59 & 47 & 45 & 36 & 59 & 47 \\
\hline Maine-Anjou & 18 & 47 & 41 & 60 & 49 & 47 & 40 & 60 & 49 \\
\hline Nelore & 22 & 51 & 35 & 52 & 48 & 51 & 35 & 51 & 47 \\
\hline Piedmontese & 29 & 49 & 61 & 78 & 72 & 47 & 60 & 73 & 72 \\
\hline Red Poll & 16 & 45 & 44 & 67 & 50 & 44 & 44 & 66 & 50 \\
\hline Sahiwal & 6 & 60 & 62 & 96 & 88 & 59 & 32 & 96 & 54 \\
\hline South Devon & 27 & 44 & 62 & 52 & 56 & 44 & 62 & 52 & 56 \\
\hline Shorthorn & 25 & 46 & 32 & 52 & 43 & 46 & 32 & 52 & 41 \\
\hline Salers & 27 & 40 & 36 & 49 & 55 & 40 & 35 & 47 & 55 \\
\hline Tarentaise & 7 & 32 & 32 & 73 & 54 & 32 & 32 & 72 & 53 \\
\hline Seven breeds ${ }^{b}$ & $340^{\mathrm{a}}$ & 1,082 & 1,003 & 1,264 & 1,091 & 1,064 & 932 & 1,241 & 927 \\
\hline Total & $673^{a}$ & 1,795 & 1,741 & 2,279 & 2,014 & 1,769 & 1,607 & 2,245 & 1,746 \\
\hline
\end{tabular}

aThese numbers correspond to number of sires for 200-d weight, but there was one less sire for 365-d weight.

bThese are the seven breeds presented in Table 2.

where $s_{i}$ is the number of sires in the $i^{\text {th }}$ sire breed and $n_{i}$ is the number of records in the $i^{\text {th }}$ sire breed.

The values in $\mathbf{G}$ and $\mathbf{R}$ depend on the following three models.

Common Variances Model (COMSB). All (co)variances were assumed to be the same across sire breeds.

Scaling Model (SCASB). All (co)variances as fractions of phenotypic variance $\left(\sigma_{\mathrm{p}}^{2}\right)$ were assumed to be the same but $\sigma_{\mathrm{p}}^{2}$ to be different for each sire breed.

Complete Model (DIFSB). (Co)variances were assumed to be different for each sire breed, except that (co)variances corresponding to dam effects were estimated in common for all sire breeds.

Heterogeneity of Variance Due to Sex. As described later, likelihood ratio tests were used to compare (co)variances and they differed $(P<.001)$ in scale, but not as fractions of phenotypic variance $(P>.10)$ by sire breed subclass. Thus, to study the nature of heterogeneity of variance due to sex and dam breed, all data (Table 3 ) were used after records were scaled to an average phenotypic standard deviation for all 22 sire breeds. Scaling was done by multiplying records by the ratio of the average phenotypic standard deviation to the phenotypic standard deviation for the corresponding sire breed.

As for the factor sire breed, three distinct sire and dam models were used to investigate heterogeneity due to sex, with a general structure similar to that of the models described before for only seven breeds. Heterosis effects for Bos taurus $\times$ Bos taurus and for Bos indicus $\times$ Bos taurus crosses were fitted as separate covariates.

Common Variances Model (COMSEX). For this model, records from the two sexes were considered to be the same trait, leaving then a model with only two traits (i.e., one for each breed of dam). (Co)variances were assumed to be the same for the two sexes. Fixed effects were fitted for each sex. In this form, the fixed effects parts of this model and the ones with four traits are equivalent. Thus, comparisons between these models can be made with likelihood ratio tests.

Scaling Model (SCASEX). Again, this was a model with four traits; however, in this case variance components as fractions of $\sigma_{\mathrm{p}}^{2}$ were assumed to be the same for both sexes within each breed of dam, but $\sigma_{p}^{2}$ were assumed different for each sex. Covariances corresponding to sire within sire breed and dam effects were obtained by assuming correlations between sexes for these effects to be unity.

Complete Model (DIFSEX). This was a regular fourtrait model with different variances for each trait and correlations different from unity.

\section{Heterogeneity of Variance Due to Dam Breed}

The approach was similar to that for heterogeneity of variance due to sex. Data from all 22 sire breeds were used.

Common Variances Model (COMDB). Records of calves from the two breeds of dam ( $\mathrm{H}$ and $\mathrm{A}$ ) were modeled as being the same trait, with sexes considered to be different traits. Fixed effects were assumed to be different for each dam breed subclass.

Scaling Model (SCADB). This is the original fourtrait model with variance components as fractions of $\sigma_{\mathrm{p}}^{2}$ assumed to be the same for both breeds of dam within each sex, but with $\sigma_{\mathrm{p}}^{2}$ assumed different for 
each breed of dam. Covariances corresponding to sire within sire breed effects were obtained with correlations between expressions of sire additive genetic effects on traits of calves from the two breeds of dam assumed to be unity.

Complete Model (DIFDB). This model is the same as the DIFSEX model.

\section{Estimation of (Co)variance Components and Model Comparisons}

Variance components were estimated by a derivative-free REML algorithm (Graser et al., 1987) using the series of computer programs, MTDFREML, developed by Boldman et al. (1993). The procedure consists of obtaining variance components that minimize -2 times the restricted log likelihood function, that is,

$$
\begin{aligned}
-2 \Lambda= & \text { constant }+\log |\mathbf{R}|+\log |\mathbf{G}| \\
& +\log |\mathbf{D}|+\log \left|\mathbf{C}_{*}\right|+\mathbf{y} \mathbf{P y}
\end{aligned}
$$

where

$$
\begin{aligned}
\mathbf{D}= & \text { the variance-covariance matrix for } \\
& \text { dam effects and is equal to the direct } \\
& \text { sum of variance- covariance matrices } \\
& \text { corresponding to each breed of dam, } \\
& \text { i.e., } \\
& \mathrm{D}=\oplus\left\{\mathbf{D}_{\mathrm{J}}\right\} \\
\mathbf{C}_{*}= & \text { a full rank submatrix of the coeffi- } \\
& \text { cient matrix for Henderson's mixed } \\
& \text { model equations; and } \\
\mathbf{y}^{\prime} \mathbf{P y}= & \text { the weighted sum of squares of the } \\
& \text { residuals. }
\end{aligned}
$$

Comparisons between models were made by likelihood ratio tests (Dobson, 1990), which consist of subtracting the minimized value of $-2 \Lambda$ for the model with more parameters from that value corresponding to the model with fewer parameters (i.e., fewer (co)variances to estimate). The difference is compared with a chi-square distribution with degrees of freedom equal to the difference in the number of parameters estimated for the two models.

The $-2 \Lambda$ values used for the common variances and the complete models were those obtained at convergence of the iterative process carried out by MTDFREML. For the scaling models, the variance component estimates as fractions of the phenotypic variance and correlations not assumed to be unity were those obtained for the models with common variances, whereas the phenotypic variances were the ones obtained for the complete models. Then, the variances and covariances calculated from those values were used with the MTDFREML program to obtain the $-2 \Lambda$ value needed to carry out the likelihood ratio test.

Because the $\log \left|C_{*}\right|$ part of $-2 \Lambda$ depends on the constraints being imposed, when models with two traits were compared to four-trait models, it was ensured that the models were equivalent with respect to the fixed part and that constraints were on the same equations for the common fixed effects of the pairs of models being compared.

Comparisons between pairs of models for each factor causing the heterogeneity of variance are defined in Table 4. By comparing the scaling models (SCA) to the different variances models (DIF), the hypotheses are tested that variance components as fractions of $\sigma_{\mathrm{p}}^{2}$ are the same across subclasses for each factor (i.e., sire breed, sex, or dam breed). The hypotheses that variance components are equal in scale across subclasses of each factor were tested by comparing the models with common variances (COM) to the scaling models.

\section{Results and Discussion}

Heterogeneity of Variance Due to Sire Breed. Results of comparisons of models are given in Table 4. For both WW and YW, variances differed $(P<.02)$ in scale but not as fractions of the phenotypic variance $(P>.10)$ by sire breed subclasses. Table 5 contains estimates of the phenotypic variances for WW and YW of calves from the four different dam breed-sex subclasses for each of the seven sire breeds that were used to study the nature of the heterogeneity of variance due to sire breed. In general, phenotypic variances were larger for heavy breeds (Charolais, Gelbvieh, and Pinzgauer) than for intermediate breeds such as Simmental, Limousin, Hereford, and Angus. Ranges of phenotypic variance estimates according to sire breed were similar for males and for females but were larger for YW than for WW (Table 5 ). However, there was not a direct relation between the means and variances.

Estimates of phenotypic variances for the rest of the 22 sire breeds were pooled over sex and dam breed by fitting a single-trait model by sire breed (Table 6) (i.e., considering weights of calves from different sex and different dam breeds as being the same trait). Variances for the Tarentaise sire breed (294 and 728 $\mathrm{kg}^{2}$ for WW and $\mathrm{YW}$, respectively), considered an intermediate breed with respect to growth (Cundiff et al., 1986), were similar to those for Jersey (233 and $686 \mathrm{~kg}^{2}$ for WW and YW, respectively) and Longhorn (345 and $721 \mathrm{~kg}^{2}$ for WW and $\mathrm{YW}$, respectively), which are breeds with small body size (Cundiff et al., 1986, 1991). The respective variances for a breed with large body size such as the Brahman ( 387 and $937 \mathrm{~kg}^{2}$ for WW and YW, respectively) also were not very different from those described above.

Pooled estimates across sexes and dam breeds were obtained for sire variances as fractions of $\sigma_{\mathrm{p}}^{2}$ for each of the seven sire breeds and for dam variances assumed to be equal for the seven sire breeds using a singletrait model (Table 7). To be equivalent to the fourtrait model with respect to the fixed effect classes, this 
Table 4. Likelihood ratio tests (LRT) of comparisons between models used to study heterogeneity of variance in 200- and 365-day weights by sire breed, sex, and dam breed ${ }^{a}$



aSeven sire breeds were used to study heterogeneity of variance due to sire breed and 22 sire breeds for heterogeneity of variance due to two sexes (males and females) and two dam breeds (Hereford and Angus).

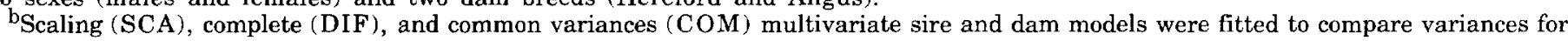
each sire breeds (SB), sex (SEX), and dam breed (DB).

$c_{\mathrm{P}}=\mathrm{P}\left(\chi_{\mathrm{df}}^{2}>\right.$ LRT $\mid$ Ho is true $)$.

single-trait model included the sire genetic group-dam breed-sex-birth year and sire genetic group-dam breed-sex-cow age subclasses as fixed effects. Analyses with data of the seven breeds together were carried out to obtain the common estimates of dam variances. Then, data sets for each sire breed were analyzed separately to estimate variances due to sire effects. Heterosis was fitted as a covariate for the analyses corresponding to the $\mathrm{H}$ and $\mathrm{A}$ sire breeds. Because of small numbers of records for each sire breed (Table 2 ), there was large variation in the respective estimates of sire variances; however, they did not differ significantly (Table 4).

Based on variance component estimates being used for National Cattle Evaluations in the United States (Pollak et al., 1994), estimates of heritabilities for additive genetic effects for weaning weight and postweaning gain are not very different among breeds, especially among those of the Bos taurus type. More differences exist in variance estimates as fractions of $\sigma_{\mathrm{p}}^{2}$ for maternal genetic and maternal environmental effects, and in estimates for the correlation between additive direct and maternal genetic effects, which were not possible to investigate in the present study.

Heterogeneity of Variance Due to Sex. The scaling model (SCASEX) accounted for as much variation ( $P$ $>$.10; Table 4) as the complete model (DIFSEX) for both WW and YW of calves when records for the two sexes were considered as being different traits; however, the model with measurements on calves from the two sexes treated as being the same trait (COMSEX) did not fit the data as well as the SCASEX model $(P<$ .001 ; Table 4). Variance components as fractions of $\sigma_{\mathrm{p}}^{2}$ can be considered to be the same for the two sexes for both WW and YW, but there are differences in scale.

Table 8 presents the estimates of variance obtained by fitting the DIFSEX model. Estimates of phenotypic

Table 5. Estimates of phenotypic variance $\left(\mathrm{kg}^{2}\right)$ by sex and dam breed for 200- and 365-day weights of calves from seven sire breeds

\begin{tabular}{|c|c|c|c|c|c|c|c|c|}
\hline Sire breed & Males & Females & Males & Females & Males & Females & Males & Females \\
\hline Hereford & 545 & 503 & 456 & 394 & 1,183 & 938 & 1,300 & 812 \\
\hline Angus & 475 & 535 & 521 & 316 & 1,025 & 858 & 1,320 & 785 \\
\hline Charolais & 706 & 514 & 600 & 601 & 1,580 & 863 & 1,666 & 814 \\
\hline Simmental & 458 & 416 & 611 & 379 & 1,081 & 940 & 1,450 & 764 \\
\hline Limousin & 473 & 290 & 545 & 439 & 1,079 & 450 & 1,183 & 690 \\
\hline
\end{tabular}


Table 6. Estimates of phenotypic variances $\left(\mathrm{kg}^{2}\right)$ of 200- and 365-day weights of calves from 15 sire breeds ${ }^{a}$

\begin{tabular}{lcc}
\hline \hline Sire breed & 200-d wt & $365-\mathrm{d}$ wt \\
\hline Brahman & 387 & 937 \\
Brown Swiss & 443 & 984 \\
Chianina & 452 & 1,031 \\
Galloway & 466 & 1,016 \\
Jersey & 233 & 686 \\
Longhorn & 345 & 721 \\
Maine-Anjou & 459 & 1,009 \\
Nelore & 573 & 1,014 \\
Piedmontese & 749 & 1,366 \\
Red Poll & 396 & 891 \\
Sahiwal & 365 & 927 \\
South Devon & 426 & 1,030 \\
Shorthorn & 575 & 1,381 \\
Salers & 573 & 1,127 \\
Tarentaise & 294 & 728 \\
\hline
\end{tabular}

${ }^{a}$ These phenotypic variance estimates were pooled over sex and dam breed with a single trait model.

variances for WW of males were 1.18 and 1.20 times the variances for females from $\mathrm{H}$ and $\mathrm{A}$ dams, respectively. For $\mathrm{YW}$, the estimates for males were 1.51 ( $\mathrm{H}$ dams) and 1.58 (A dams) times the variances for females. Larger variances in males than in females is commonly reported (e.g., Aaron et al., 1987; Alenda and Martin, 1987; Buchanan et al., 1982; Garrick et al., 1989). Also in Table 8 are estimates of sire within sire breed and dam variances as fractions of phenotypic variance, and correlations for these effects among the four sex-dam breed subclasses. From the variance estimates for sire effects on WW, the heritability $\left(\mathrm{h}^{2}\right)$ estimates for direct additive genetic effects were .24 and .28 for males and .20 and .28 for females from $\mathrm{H}$ and $\mathrm{A}$ dams, respectively. The $\mathrm{h}^{2}$ estimates for $\mathrm{YW}$ were .48 and .52
Table 7. Pooled estimates over sexes and dam breeds for phenotypic variance $\left(\sigma_{\mathrm{p}}^{2} \mathrm{~kg}^{2}\right)$ and sire variance $\left(s^{2}\right)$ as fraction of $\sigma_{p}^{2}$ for 200- and 365-day weights of calves from seven sire breeds ${ }^{a}$

\begin{tabular}{llllll}
\hline \hline & \multicolumn{2}{c}{$200-\mathrm{d}$ wt } & & \multicolumn{2}{c}{$365-\mathrm{d}$ wt } \\
\cline { 2 - 3 } \cline { 5 - 6 } $\begin{array}{l}\text { Sire } \\
\text { breed }\end{array}$ & $\mathrm{s}^{2}$ & $\sigma_{\mathrm{p}}^{2}$ & & $\mathrm{~s}^{2}$ & $\sigma_{\mathrm{p}}^{2}$ \\
\hline Hereford & .04 & 444 & & .10 & 1,058 \\
Angus & .10 & 469 & & .21 & 1,086 \\
Charolais & .07 & 630 & & .15 & 1,310 \\
Gelbvieh & .04 & 579 & & .13 & 1,249 \\
Pinzgauer & .12 & 589 & & .20 & 1,388 \\
Simmental & .07 & 468 & & .11 & 1,087 \\
Limousin & .02 & 446 & & .10 & 857 \\
\hline
\end{tabular}

aThese variance component estimates were pooled over sex and dam breed with a single trait sire and dam model with common dam variances as fractions of $\sigma_{\mathrm{p}}^{2}$ being .37 for $\mathrm{WW}$ and .24 for $\mathrm{YW}$.

for males and .44 and .56 for females from $\mathrm{H}$ and $\mathrm{A}$ dams, respectively. Differences as large or larger between $h^{2}$ estimates for weaning and yearling weights on calves of the two sexes have been reported previously for Santa Gertrudis (Aaron et al., 1987), Angus (Alenda and Martin, 1987), Hereford (Buchanan et al., 1982), Angus and Hereford (Bourdon and Brinks, 1982), and Simmental (Burfening et al., 1978; Garrick et al., 1989). In most of the cases, the standard errors for the $\mathrm{h}^{2}$ estimates obtained in these studies are large enough to preclude statistical significance on the differences. Using a large amount of data, Garrick et al. (1989) found differences of .01 to .07 in $\mathrm{h}^{2}$ estimates for $\mathrm{WW}$ of male and female calves with different percentages of Simmental and differences of .02 to .06 for postweaning daily gain. Also, $\mathrm{h}^{2}$ estimates obtained by mixed-model least

Table 8. Pooled estimates over breeds of sire, for variances as fractions of phenotypic variance $\left(\sigma_{\mathrm{p}}^{2}\right)$ for sire (dam) effects (diagonal), and correlations

among sire (below diagonal) and dam (above diagonal) effects on expression of 200- and 365-day weights $(\mathrm{kg})$ of male $(\mathrm{M})$ and female $(\mathrm{F})$

calves out of Hereford (H) and Angus (A) dams

\begin{tabular}{|c|c|c|c|c|c|}
\hline \multicolumn{6}{|l|}{ Dam } \\
\hline breed-Sex & $\mathrm{H}-\mathrm{M}$ & $\mathrm{H}-\mathrm{F}$ & A-M & A-F & $\sigma_{\mathrm{p}}^{2}$ \\
\hline & & & $200-d w t$ & 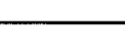 & \\
\hline $\mathrm{H} \cdot \mathrm{M}$ & $.06(.46)$ & 1.00 & - & - & 534 \\
\hline $\mathrm{H}-\mathrm{F}$ & .93 & $.05(.40)$ & - & - & 454 \\
\hline A-M & .91 & .99 & $.07(.35)$ & 1.00 & 483 \\
\hline$A-F$ & .86 & .98 & .99 & $.07(.35)$ & 403 \\
\hline H-M & $.12(.27)$ & 1.00 & - & - & 1,226 \\
\hline H-F & .94 & $.11(.30)$ & - & - & 815 \\
\hline A-M & .95 & .98 & $.13(.23)$ & 1.00 & 1,218 \\
\hline$A-F$ & .85 & .97 & .92 & $.14(.24)$ & 770 \\
\hline
\end{tabular}


Table 9. Pooled estimates over sire and dam breeds, for variances as fractions of the phenotypic variance $\left(\sigma_{\mathrm{p}}^{2}\right)$ for sire (dam) effects (diagonal), and correlations between sire (below diagonal) and dam (above diagonal) effects on expression of 200- and 365-day weights $(\mathrm{kg})$ of male and female calves

\begin{tabular}{|c|c|c|c|}
\hline Sex & Males & Females & $\sigma_{\mathrm{p}}^{2}$ \\
\hline & \multicolumn{2}{|c|}{$200-\mathrm{d} w \mathrm{wt} \longrightarrow$} & \\
\hline Males & $.06(.41)$ & 1.00 & 511 \\
\hline \multirow[t]{2}{*}{ Females } & 1.00 & $.05(.38)$ & 425 \\
\hline & \multicolumn{2}{|c|}{ 365-d wt $\longrightarrow$} & \\
\hline Males & $.11(.25)$ & 1.00 & 1,207 \\
\hline Females & .92 & $.12(.27)$ & 791 \\
\hline
\end{tabular}

squares procedures reported by Buchanan et al. (1982) for Herefords were statistically different between sexes, especially for yearling weight $(.23 \pm .02$ and $.37 \pm .03$ for bull and heifer calves, respectively). However, there was not such a difference when the same data were analyzed with an animal model and REML procedures (Koch, 1994; personal communication). Mohiuddin (1993) did an extensive review on genetic parameters obtained around the world for some performance traits in beef cattle. The average $h^{2}$ estimates reported for male and female calves, respectively, were .26 and .23 for weaning weight and .49 and .48 for yearling weight.

Additive genetic correlations between weight traits in the two sexes were .93 and .99 for WW and .94 and .92 for $\mathrm{YW}$ on calves from $\mathrm{H}$ and $\mathrm{A}$ dams, respectively (Table 8). No other reports of these correlations using a multivariate model were found. Garrick et al. (1989) obtained approximations of these correlations by comparing observed and expected correlations of estimated predicted differences computed in independent data sets for each sex-percentage Simmental combination. In general, they found that the observed correlations were similar to the expected ones, except for postweaning gain. They concluded that the genetic correlation between a random factor in each sexpercentage subclass likely is close to unity. Therefore, a large fraction of additive genes for the weight traits have the same effect with regard to controlling variation in each subclass considered.

Estimates of variances due to dam effects, as fractions of $\sigma_{\mathrm{p}}^{2,}$ were relatively high (.35 to .46 for WW and .23 to .30 for $\mathrm{YW}$ ) compared with what was expected from variances of additive direct and maternal genetic and environmental maternal effects reported in the literature and summarized by Meyer (1992) and Mohiuddin (1993). A possible explanation could be a large positive covariance between direct and maternal genetic effects, although, most of the estimates summarized in the reviews are negative.
Table 10. Pooled estimates over breeds of sire and sexes, for variances as fractions of the phenotypic variance $\left(\sigma_{\mathrm{p}}^{2}\right)$ for sire (dam) effects (diagonal), and correlations between sire (below diagonal) effects on expression of 200- and 365-day weights $(\mathrm{kg})$ of calves out of Hereford and Angus dams

\begin{tabular}{|c|c|c|c|}
\hline Dam breed & Hereford & Angus & $\sigma_{\mathrm{p}}^{2}$ \\
\hline & 200 & wt & \\
\hline Hereford & $.05(.43)$ & - & 493 \\
\hline \multirow[t]{2}{*}{ Angus } & .97 & $.07(.35)$ & 444 \\
\hline & -36 & wt & \\
\hline Hereford & $.11(.26)$ & - & 1,026 \\
\hline Angus & 1.00 & $.12(.22)$ & 1,008 \\
\hline
\end{tabular}

Correlations between dam effects for sexes were near unity in all cases (Table 8).

Pooled estimates of the variance components across sexes were obtained by fitting the COMSEX model and are presented in Table 9 . The values are generally the average of the ones obtained with the DIFSEX model (Table 8).

Heterogeneity of Variance Due to Dam Breed. Variance components were not different $(P>.10)$ by dam breed subclasses, either in scale or as fractions of $\sigma_{\mathbf{p}}^{2}$ (Table 4). Phenotypic variances for WW of calves from $\mathrm{H}$ dams were only 1.11 and 1.13 times those for male and female calves from A dams, respectively. For YW, phenotypic variances for male and female calves from $\mathrm{H}$ dams, respectively, were 1.01 and 1.06 times those for calves from A dams (Table 8). Table 9 contains the variance component estimates obtained with the COMDB model. The pooled estimates of the different variances across dam breeds were basically the average of those obtained when measurements on calves from different dam breeds were treated as being different traits (Table 8).

The estimates of the sire variance components as fractions of $\sigma_{\mathrm{p}}^{2}$, for both WW and $\mathrm{YW}$, are quite similar for calves from the $\mathrm{H}$ and A dam breeds (Table 10). However, the estimates of the variances for dam effects on WW of calves from the two dam breeds, $\mathrm{H}$ and $A$, present a proportional difference of .08 . This explains the relatively high value (12.3) of the likelihood ratio test ( $P=.27$; Table 4) for the hypothesis of equality of variances as fractions of $\sigma_{p}^{2}$ for the two dam breeds, compared with the values obtained for the tests of differences in fractions for sire breeds and sexes $(P>.95)$, even though neither was significant. Most of the differences among breeds in variances as fractions of $\sigma_{\mathrm{p}}^{2}$, as presented by Pollak et al. (1994), are with respect to additive genetic maternal and environmental maternal variances and to the correlations between additive genetic direct and 
maternal effects. Meyer (1992) presented estimates of variance components for Australian Hereford and Angus cattle. Weaning weight in Herefords was primarily determined by permanent environmental effects due to the dam, whereas for weaning weight in Angus those effects were of little importance. Estimates of the variance components as fractions of $\sigma_{\mathrm{p}}^{2}$ corresponding to direct $\left(\mathrm{h}^{2}\right)$ and maternal $\left(\mathrm{m}^{2}\right)$ additive genetic effects and maternal permanent environmental $\left(\mathrm{c}^{2}\right)$ effects on weaning weight were, respectively, $.14 \pm .03, .13 \pm .03$, and $.23 \pm .02$ for Hereford and $.20 \pm .05, .14 \pm .04$, and $.04 \pm .02$ for Angus. Estimates presented by Pollak et al. (1994) for weaning weight data used in the National Cattle Evaluations in the United States for these two breeds are $.24, .24$, and .02 for Hereford and $.29, .24$, and .08 for Angus, for $\mathrm{h}^{2}, \mathrm{~m}^{2}$, and $\mathrm{c}^{2}$, respectively. Also, differences between the two breeds were found by Meyer (1992) for the correlation between direct and maternal genetic effects, with values of -.59 and .22 for weaning weight of Hereford and Angus cattle, respectively. The corresponding estimates presented by Pollak et al. (1994) are -.28 and -.33 . Pollak et al. (1994) reported only one positive correlation estimate (.15) between direct and maternal genetic effects, and this was for the Brahman breed.

Estimates of correlations between sire effects on traits of calves from $\mathrm{H}$ and $\mathrm{A}$ dams were .97 and 1.00 for WW and YW, respectively (Table 10). In some studies (Koger et al., 1975; Massey and Benyshek, 1981; Núñez-Domínguez et al., 1993), this type of correlation has been taken to be an indicator of sire $\times$ breed of dam interactions. The interaction effect also has been tested by analysis of variance (Koger et al., 1975; Massey and Benyshek, 1981). With this latter approach alone, however, it is not possible to determine whether the interaction is due to scaling or to reranking of the sire genetic values when mated to cows of different breeds. Reranking can be assessed by looking at the genetic correlation between the genetic values of sires used with different dam breeds.

Because the estimates of correlations obtained in the present study are not different from unity for either WW or YW, minimum reranking of genetic values of sires when used with different dam breeds will occur. Using part of these data and an animal model, Núnez-Domínguez et al. (1993) obtained estimates of these genetic correlations for each of 12 sire breeds. On average, they reported estimates of correlations of .73 and .86 for $\mathrm{WW}$ and $\mathrm{YW}$, respectively, and concluded that some reranking of sire genetic values for WW could occur when sires are mated to $\mathrm{H}$ or A cows; however, they recognized that their estimates could have large standard errors due to the small number of records for each sire breed. Massey and Benyshek (1981) found that the interaction when Limousin sires were mated to $\mathrm{H}$ and $\mathrm{A}$ cows was significant but accounted for only .61 and $1.43 \%$ of the total variance for 205- and 365-d weights, respectively. Correlations between responses in Hereford and Angus crosses were .78 and .62 for 205- and 365-d weights, respectively. In an earlier study involving purebred and crossbred animals of the H, A, and Brahman breeds, Koger et al. (1975) did not find a significant interaction between sire within year and breed of dam effects on 205-d weight. The estimated genetic correlations between paternal halfsib families for different classes of dams ranged from .98 to 1.24 , but with large standard errors.

Use of Likelihood Ratio Tests. Likelihood ratio tests (LRT) are appropriate statistical procedures to compare fitness of models when the parameter values are not at the boundaries of the parameter space. Table 4 shows that when comparing the scaling models (SCA) to the different (co)variances models (DIF) most of the probabilities of finding a chi-square value larger than the LRT values, given that the null hypothesis was true, were close to one. These large probabilities are due to the fact that for the scaling models, according to sex and dam breed, some correlations were set close to unity (e.g., .999) instead of unity. Also, when studying the sire breed factor, the variance-covariance structure for dam effects was assumed common for all sire breeds and scaling was not considered. Under this situation the SCASB model is not a special case of the DIFSB model. Thus, the corresponding probabilities are only approximations of the true probability values. However, the increases in the $-2 \Lambda$ values from the models with different variances (DIF) to the scaling models (SCA) were so small, compared with the complexity of the DIF models, that the conclusions obtained are not likely to change under more precise conditions. With tests to compare models, such as "Akaike's Information Criterion" (Akaike, 1974) and "Schwartz's Bayesian Criterion" (Schwartz, 1978), the SCA models were preferred to the DIF models. Therefore, the problem was not pursued any further.

\section{Implications}

Variants of the animal model are commonly used for National Cattle Evaluations within breeds. If a version of the animal model were implemented to carry out multibreed genetic evaluations, that model should take into account differences in phenotypic variances among breeds and between sexes for $200-$ and 365-d weights. Differences in variances due to maternal effects among breeds also should be considered; in the present study only two breeds of dam were used. Correlations between random sire and dam effects for 200- and 365-d weights of calves from different sex-dam breed subclasses were not different from unity. Thus, simplifications for a multivariate animal model to account for heterogeneous variances could be applied for these traits. 


\section{Literature Cited}

Aaron, D. K., F. A. Thrift, and N. R. Parish. 1987. Genetic parameter estimates for preweaning growth traits in Santa Gertrudis cattle. J. Anim. Sci. 65:1495.

Akaike, H. 1974. A new look at the statistical model identification. IEEE Transaction on Automatic Control, AC-19. pp 716-723.

Alenda, R., and T. G. Martin. 1987. Genetic parameters and consequences of selection for growth traits in a beef herd selected for yearling weight. J. Anim. Sci. 64:366.

Arnold, J. W., J. K. Bertrand, and L. L. Benyshek. 1992. Animal model for genetic evaluation of multibreed data. J. Anim. Sci. $70: 3322$.

Boldman, K. G., L. A. Kriese, L. D. Van Vleck, and S. D. Kachman. 1993. A manual for use of MTDFREML. A set of programs to obtain estimates of variances and covariances. ARS, USDA, USMARC, Clay Center, NE.

Bourdon, R. M., and J. S. Brinks. 1982. Genetic, environmental and phenotypic relationships among gestation length, birth weight, growth traits and age at first calving in beef cattle. J. Anim. Sci. 55:543.

Buchanan, D. S., M. K. Nielsen, R. M. Koch, and L. V. Cundiff. 1982. Selection for growth and muscling score in beef cattle. II. Genetic parameters and predicted response. J. Anim. Sci. 55: 526.

Burfening, P. J., D. D. Kress, R. L. Friedrich, and D. Vaniman. 1978. Calving ease and growth rate of Simmental-sired calves. II. Genetic parameter estimates. J. Anim. Sci. 46:930.

Cundiff, L. V. 1994. Procedures for across breed EPD's. Proc. of the Fourth Genetic Prediction Workshop. Kansas City, MO.

Cundiff, L. V., K. E. Gregory, and R. M. Koch. 1993. Characteristics of diverse breeds in Cycle IV of the cattle germplasm evaluation program. USDA, ARS-Beef Research Progress Rep. No. 4. pp 57-60.

Cundiff, L. V., K. E. Gregory, R. M. Koch, J. D. Crouse, and M. E. Dikeman. 1991. Characteristics of diverse breeds in cycle IV of the cattle germ plasm evaluation program at the U. S. Meat Animal Research Center. Proc. Range Beef Cow Symp. XII. Fort Collins, CO. p 61.

Cundiff, L. V., K. E. Gregory, R. M. Koch, and G. E. Dickerson. 1986. Genetic diversity among cattle breeds and its use to increase beef production efficiency in a temperate environment. Proc. 3rd World Congr. Genet. Appl. Livest. Prod. 9:271.

Cundiff, L. V., K. E. Gregory, T. L. Wheeler, S. D. Shackelford, M. Koohmaraie, H. C. Freetly, and D. D. Lunstra. 1994. Preliminary results from Cycle $\mathrm{V}$ of the cattle germplasm evaluation program at the Roman L. Hruska U.S. Meat Animal Research Center. USDA, ARS-Germ Plasm Evaluation Program Progress Rep. No. 13.

Cundiff, L. V., R. M. Koch, and K. E. Gregory. 1984. Characterization of biological types of cattle (Cycle III). IV. Postweaning growth and feed efficiency. J. Anim. Sci. 58:312.

Cundiff, L. V., R. M. Koch, K. E. Gregory, and G. M. Smith. 1981. Characterization of biological types of cattle-Cycle II. IV. Postweaning growth and feed efficiency of steers. J. Anim. Sci. 53:332.

Dobson, A. J. 1990. An Introduction to Generalized Linear Models. p 57. Chapman and Hall, New York.

Elzo, M. A., and T. R. Famula. 1985. Multibreed sire evaluation procedures within a country. J. Anim. Sci. 60:942.

Garrick, D. J., E. J. Pollak, R. L. Quaas, and L. D. Van Vleck. 1989. Variance heterogeneity in direct and maternal weight traits by sex and percent purebred for Simmental-sired calves. J. Anim. Sci. 67:2515.

Gianola, D. 1986. On selection criteria and estimation of parameters when the variance is heterogeneous. Theor. Appl. Genet. 72: 671.

Graser, H.-U., S. P. Smith, and B. Tier. 1987. A derivative-free approach for estimating variance components in animal models by restricted maximum likelihood. J. Anim. Sci. 64:1362.

Gregory, K. E., L. V. Cundiff, G. M. Smith, D. B. Laster, and H. A. Fitzhugh, Jr. 1978. Characterization of biological types of cattle--Cycle II: I. Birth and weaning traits. J. Anim. Sci. 47:1022.

Gregory, K. E., D. B. Laster, L. V. Cundiff, G. M. Smith, and R. M. Koch. 1979a. Characterization of biological types of cattleCycle III: II. Growth rate and puberty in females. J. Anim. Sci. 49:461.

Gregory, K. E., G. M. Smith, L. V. Cundiff, R. M. Koch, and D. B. Laster. 1979b. Characterization of biological types of cattle-Cycle III: I. Birth and weaning traits. J. Anim. Sci. 48:271.

Henderson, C. R. 1984. Linear Models in Animal Breeding. p 439. University of Guelph Press, Guelph, Ontario, Canada.

Koger, M., A. F. Jilek, W. C. Burns, and J. R. Crockett. 1975. Sire effects for specific combining ability in purebred and crossbred cattle. J. Anim. Sci. 40:230.

Massey, M. E., and L. L. Benyshek. 1981. Interactions involving sires, breed of dam and age of dam for performance characteristics in Limousin cattle. J. Anim. Sci. 53:940.

Meyer, K. 1992. Variance components due to direct and maternal effects for growth traits of Australian beef cattle. Livest. Prod. Sci. 31:179.

Mohiuddin, G. 1993. Estimates of genetic and phenotypic parameters of some performance traits in beef cattle. Anim. Breed. Abstr. 61:495.

Notter, D. R. 1989. EPD for use across breeds. 21st Mtg. of the Beef Improvement Federation. Nashville, TN. p 63.

Núñez-Domínguez, R., L. D. Van Vleck, K. G. Boldman, and L. V. Cundiff. 1993. Correlations for genetic expression for growth of calves of Hereford and Angus dams using a multivariate animal model. J. Anim. Sci. 71:2330.

Núñez-Domínguez, R., L. D. Van Vleck, and L. V. Cundiff. 1995. Prediction of genetic values for growth traits of crossbred cattle using a multivariate animal model with heterogeneous variances. J. Anim. Sci. (In press).

Pollak, E. J., C. S. Wang, B. E. Cunningham, L. Klei, and C. P. Van Tassell. 1994. Consideration of the validity of parameters used in national cattle evaluations. Proc. of the Fourth Genetic Prediction Workshop. Kansas City, MO.

Quaas, R. L., D. J. Garrick, and W. H. McElhenney. 1989. Multiple trait prediction for a type of model with heterogeneous genetic and residual covariance structures. J. Anim. Sci. 67:2529.

Schwartz, G. 1978. Estimating the dimension of a model. Ann. of Stat. 6:461.

Smith, G. M., D. B. Laster, L. V. Cundiff, and K. E. Gregory. 1976a. Characterization of biological types of cattle II. Postweaning growth and feed efficiency of steers. J. Anim. Sci. 43:37.

Smith, G. M., D. B. Laster, and K. E. Gregory. 1976b. Characterization of biological types of cattle I. Dystocia and preweaning growth. J. Anim. Sci. 43:27.

Van Vleck, L. D. 1994. Prediction error variances for inter-breed EPD's. Proceedings of the Fourth Genetic Prediction Workshop. Kansas City, MO.

Vinson, W. E. 1987. Potential bias in genetic evaluations from differences in variation within herds. J. Dairy Sci. 70:2450. 